\title{
Geophysics in oil exploration
}

\author{
J.L. Fatti \\ Soekor (Pty.) Ltd., P.O. Box 3087, Johannesburg 2000
}

\begin{abstract}
The reflection seismic technique is the most widely used geophysical method world-wide, being used mainly in oil exploration. It is an echo-sounding technique for mapping the tectonic structure of layered sedimentary rocks. Seismic waves are induced in the ground, typically from an explosive source, and they are reflected at each geological boundary where there is a change in acoustic impedance (acoustic impedance is the product of density and seismic velocity). The reflected waves are detected at the surface using geophones on land, or hydrophones at sea. The outputs from the detectors are recorded on digital magnetic tape and are then computer-processed. A field technique called common-depth-point recording is used so that noise and multiple reflections can be cancelled by "stacking", which is carried out during the computer processing. In the computer various types of filters are applied to the seismic results to remove noise, to improve resolution, and to correct geometrical distortion which occurs in areas of complex tectonic structure.

The final output is displayed as a seismic record section, which is made up of many individual seismic traces, and resembles a cross-section through the earth, showing the structure of the sedimentary rocks.

Very high-quality reflection seismic results have been obtained on the South African continental shelf, and have been extremely valuable in siting oil exploration wells.
\end{abstract}

\section{UITTREKSEL}

\section{Geofisika in olie-eksplorasie}

Die mees algemeen gebruikte geofisiese metode wêreldwyd, veral ten opsigte van olie-eksplorasie, is die seismiese refleksietegniek. Dit is 'n eggoweerkaatsingstegniek vir die kartering van die tektoniese struktuur van sedimentêre gesteentes. Seismiese golwe word in die grond veroorsaak deur 'n ontploffing, en sodanige golwe weerkaats van elke geologiese grens waar daar ' $n$ verandering in akoestiese impedansie is. (Akoestiese impedansie is die produk van digtheid en seismiese snelheid van 'n gesteente). Die weerkaatste golwe word op die oppervlakte waargeneem deur geofone op land, of hidrofone ter see. Hierdie waarnemings word op magnetiese band vasgelê en dan deur ' $n$ rekenaar verwerk. Spesiale veldtegnieke word gebruik om geruis en veelvoudige weerkaatsings te verminder.

Die doel van die verwerking van die seismiese resultate deur ' $n$ rekenaar is om die res van die geruis en veelvoudige weerkaatsings uit te sny, asook om geometriese verdraaiings, wat veroorsaak word deur komplekse geologiese strukture, te korrigeer. Die finale produk is n seismiese profiel, wat bestaan uit baie individuele seismiese rekords, en wat die struktuur van die sedimentêre lae aantoon.

Seismiese opnames van baie hoë gehalte is op die Suid-Afrikaanse vastelandsplat verkry, en is uiters waardevol by die beplanning van boorgatposisies.

\section{INTRODUCTION}

Geophysical methods which are used in exploration for oil and gas include gravimetric surveys, magnetometric surveys, seismic reflection and seismic refraction surveys. By far the most extensively used is the seismic reflection method. This technique will be described in the present paper.

In 1978 a total of 1672 million US dollars was spent on all methods of geophysical exploration world-wide. Of this, 93 per cent was spent on seismic reflection surveys for oil, onshore and offshore. ${ }^{1}$ As a result of its extensive use, the technology in reflection seismic prospecting has been advancing rapidly, especially in the last twenty years.

Oil pools are located in porous reservoir rocks, usually sandstones or porous limestones. The reservoir must be overlain by an impermeable "cap rock" such as shale, and there must be a geological trapping mechanism which confines the oil to the pool. There are two basic classes of traps (see Fig. 1): structural traps, such as anticlines and fault traps, and strati- (a)

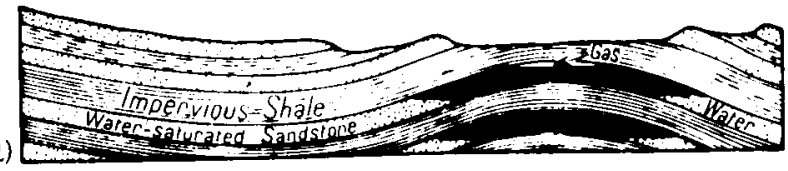

(b)
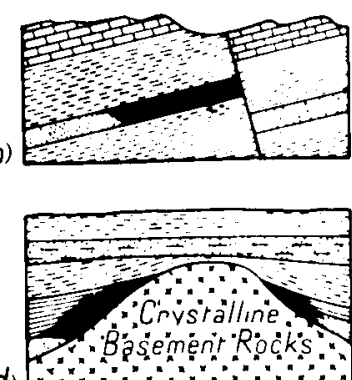

(d) $\because \cdots \cdots \cdots \cdots$

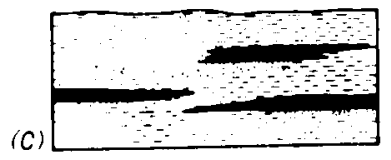

(e)

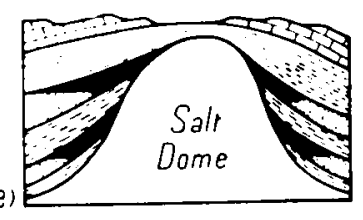

FIGURE 1. Common oil traps: (a) Anticline or dome structure (Structural trap); (b) Fault trap (structural trap); (c) Sandstone lenses in shale country rock (stratigraphic trap); (d) Sandstone pinch-outs on the flanks of a basement high (structural/stratigraphic trap); (e) Sandstone pinch-outs on the flanks of a salt dome (structural trap). (After Holmes ${ }^{4}$ p. 350) 
graphic traps, such as erosional unconformities and sandstone "wedge-outs" or "shale-outs".

Exploration for trap structures is usually done using the reflection seismic method. Basically, it is an echo-sounding technique using seismic waves, which are low-frequency sound waves. Seismic reflection surveys have often been successful in locating structural features which produce traps, such as anticlines and faults. Stratigraphic traps have also been discovered with the reflection seismograph, but this type of trap is more difficult to locate.

Detailed descriptions of the seismic reflection method are contained in work by Dobrin ${ }^{2}$ and Waters $^{3}$.

\section{PRINCIPLES OF THE EXPLORATION SEISMIC METHOD}

Figure 2 shows the basic field layout for the reflection seismic survey on land. The source of seismic waves is typically a charge of dynamite, which is placed at the bottom of a "shot-hole", drilled for this purpose. The shot-hole is typically about $20-30 \mathrm{~m}$ deep. The dynamite shot produces compressional elastic (seismic) waves, which travel radially out from the shotpoint. The frequency of the seismic waves used for deep investigation seismic surveys is in the range 5 to $60 \mathrm{~Hz}$. For shallow surveys ( 200 to $1000 \mathrm{~m}$ deep) the frequency range is 40 to $150 \mathrm{~Hz}$. Other methods on land use mechanical vibrators, weightdropping, and surface explosive charges as energy sources.

The waves travelling outward from the shotpoint are refracted at geological interfaces according to Shell's law due to the change in seismic velocity from one formation to another. Seismic energy is also reflected from each geological interface. The amplitude of a reflection is proportional to the reflection coefficient of the interface, which is given by the formula:

$R_{12}=\frac{V_{2} d_{2}-V_{1} d_{1}}{V_{2} d_{2}+V_{1} d_{1}} \ldots$

where: $R_{12}=$ Reflection coefficient of the interface between layer 1 and layer $2=$ ratio of the amplitude of the reflected wave to the amplitude of the incident wave.

$\mathrm{V}_{2}=$ Velocity of layer 2

$V_{1}=$ Velocity of layer 1

$\mathrm{d}_{2}=$ Density of layer 2

$d_{1}=$ Density of layer 1

Vd $=$ Acoustic impedance

The reflected waves which return to the surface are detected by groups of geophones (or seismometers). A geophone is an electro-mechanical device which produces an electrical signal proportional to the velocity of ground movement. Groups (or arrays) of geophones are used rather than individual geophones in order to attenuate horizontally travelling waves, such as refractions through the near-surface layers and surface-travelling waves, which obscure the reflected waves. Geophones in a group are connected in such a manner as to give directional sensitivity: reflections arriving from below are passed, but refraction arrivals and other types of noise arrivals which are generated by the shot and which travel horizontally are attenuated by the geophone group.

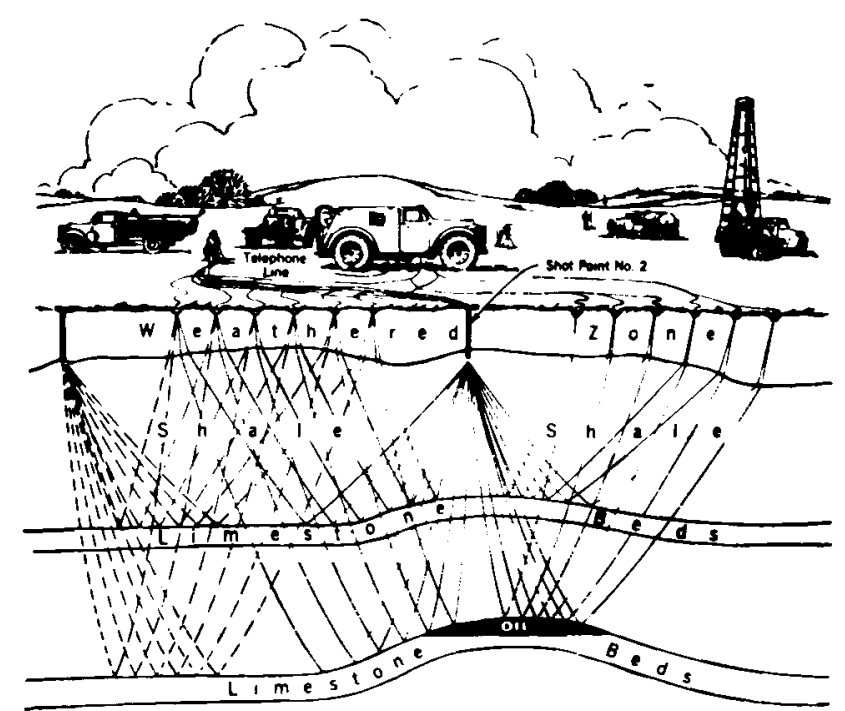

FIGURE 2. A reflection seismic survey being carried out on land. For simplicity, the detectors are shown as 12 individual geophones, whereas in practice each geophone in the figure would be a group of geophones. (After Landes, ${ }^{5}$ p. 8I)

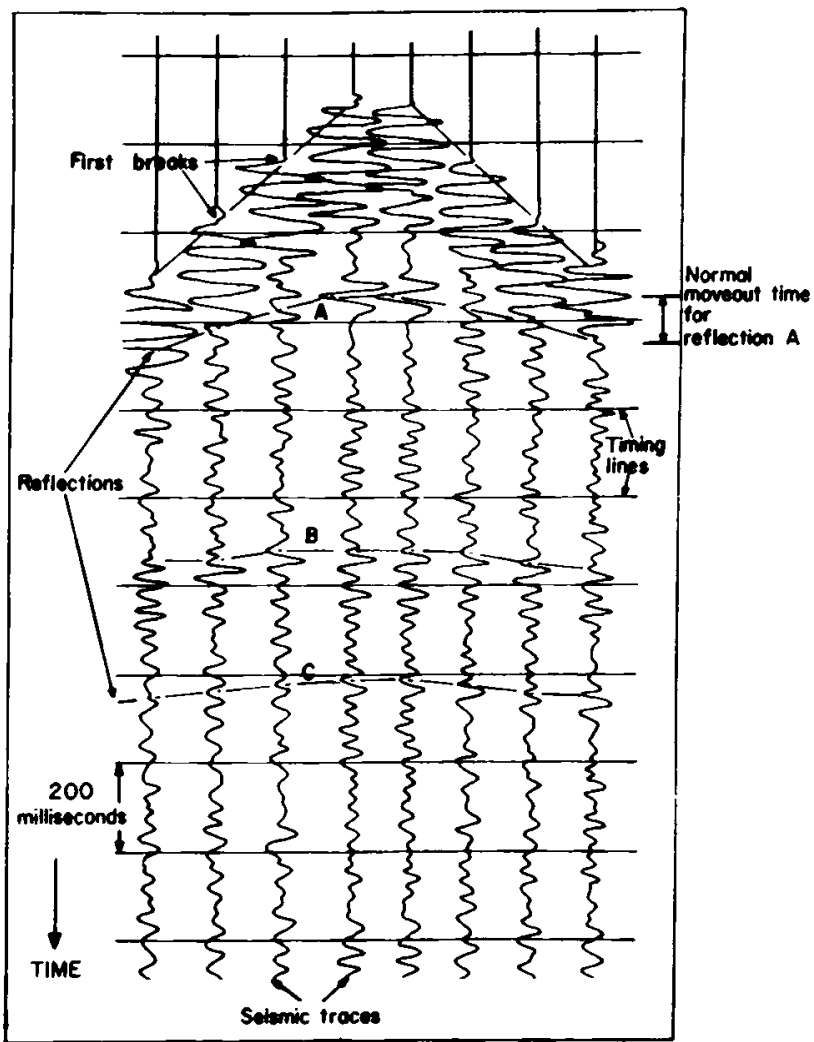

FIGURE 3a. A field seismic record, using eight geophone groups. Each group produces a "wigglyline" trace. Reflections $A, B$ and $C$ can be recognized by their hyperbolic curvatures, the curvature decreasing with increasing time (depth). The shotpoint is in the middle of the record, between traces 4 and 5 . (After Coffeen, ${ }^{6}$ p. 24) 
Figure $3 a$ is a field seismic record. This is the result of one recording. Each of the geophone groups produces a "wiggly line" or "trace" output. Usually there are 24,48 , or even 60 groups of geophones. The first energy (called first breaks) to arrive at the geophones are the refraction arrivals, which travel in the near-surface layers. Then follow the reflections from underlying geological interfaces. Reflections have a hyperbolic shape on a field record because of the increasing travel-path distance for increasing separation between source and receiver.

For a horizontal interface this hyperbola is given approximately by:

$$
\mathrm{T}^{2}=\mathrm{T}_{0}^{2}+\mathrm{X}^{2} / \mathrm{V}^{2} \ldots
$$

where $\mathrm{T}=$ Travel time along a slanting raypath, down and up, corresponding to the receiver at distance $X$.

$T_{0}=$ Travel time along the vertical raypath, down and up.

$\mathrm{X}=$ Distance between source and receiver.

$\mathrm{V}=$ Average seismic velocity over the travel path from the surface down to the reflector. The average velocity is equal to the depth of the reflector divided by the vertical travel time to the reflector.

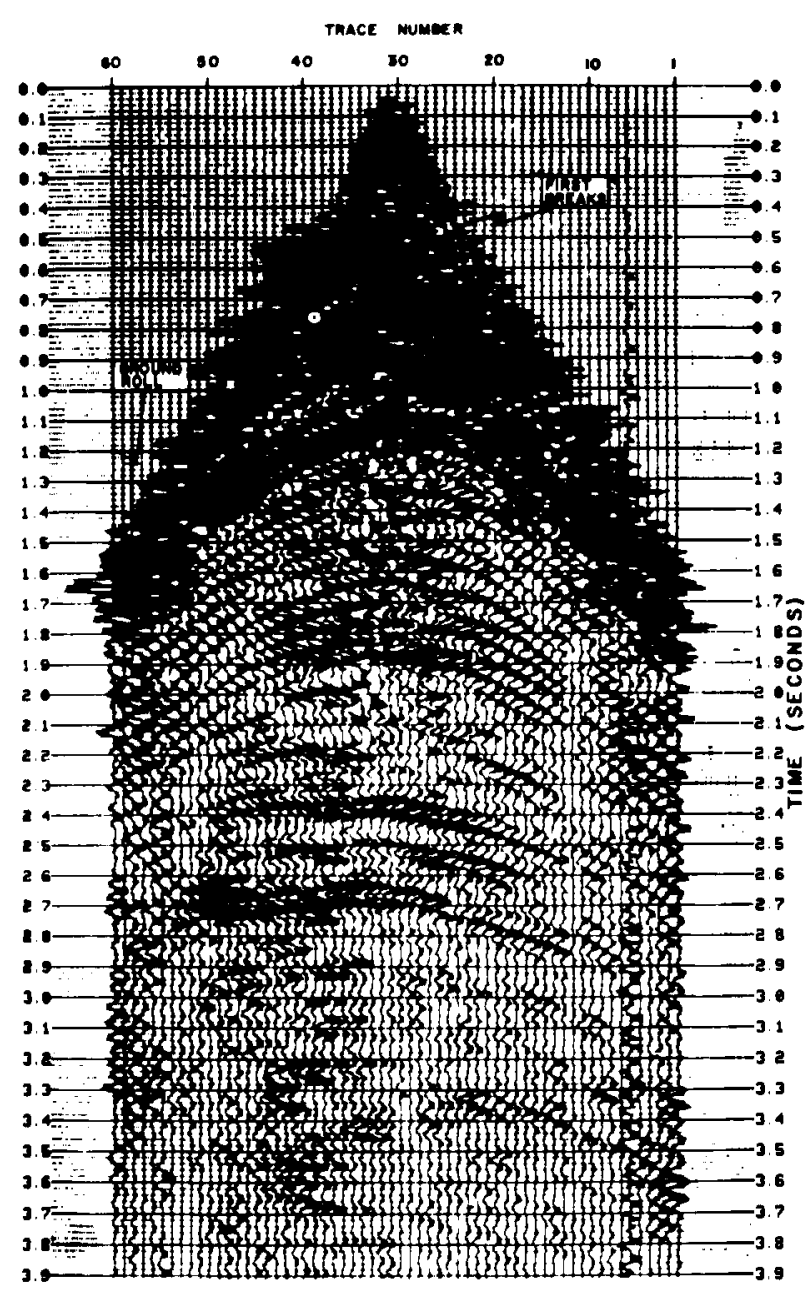

FIGURE 3b. A 60-trace seismic field record. The shotpoint is in the middle of the spread, between traces 30 and 31. Reflections can be seen between 0,7 sec and 2,8 sec. (After Coffeen, ${ }^{6}$ p. 31)

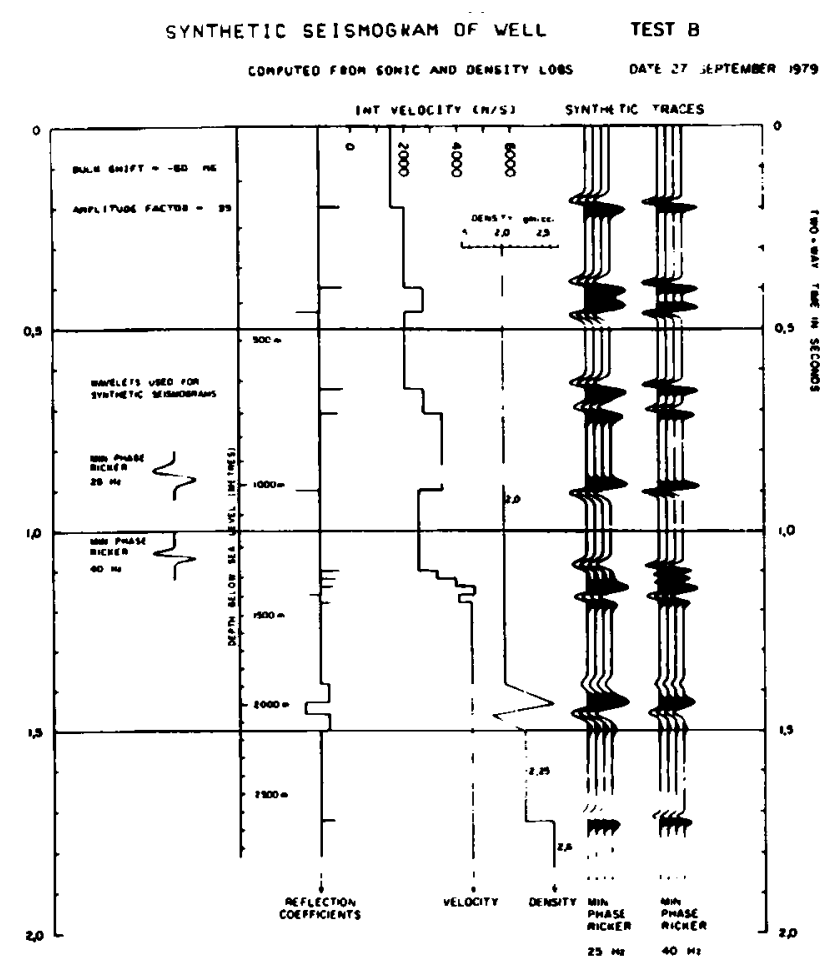

FIGURE 4a. The two groups of traces on the right are normal-incidence "synthetic" seismograms, calculated from the velocity and density distribution in the centre. The two seismograms have been calculated assuming two different wavelets: a low-frequency (25 Hz) minimum-phase Ricker wavelet, and a higher-frequency $(40 \mathrm{~Hz})$ Ricker wavelet. The traces have been moved upwards by 60 milliseconds so that the centre of each reflection wavelet corresponds in time to the reflector as shown on the velocity or density curves.

In addition to reflections, there are many tyes of noise arrivals on seismic records. Some of the noise is random; other types of noise are coherent across the record, such as refraction arrivals and ground roll, which are generated by the shot and sometimes arrive at the receiver at the same time as reflections. Ground roll is low-frequency energy which travels in the surface layers, directly from source to receiver. Figure $3 b$ is a 60 -trace seismic field record. The hyperbolically curved reflections can be seen clearly on the record, and the curvature decreases downwards. The shotpoint is in the centre of the record, between traces 30 and 31 . For deep-investigation seismic surveys, records are usually 6 seconds long.

Figure 4(a) is a theoretical ("synthetic") seismogram for vertical incidence for a simple geological model. One can see that for layer thickness of less than a wavelength (about $100 \mathrm{~m}$ ) the reflections overlap to produce a composite reflection. Figure $4(\mathrm{~b})$ shows the theoretical seismogram calculated from the actual velocity distribution measured in a well. In general the effects of velocity variations are much more important than the effects of density variations in producing reflections, and density has been left out of this calculation. The velocity variation with depth is fairly rapid, and every velocity change produces a reflection. In most cases, therefore, reflec- 
tions overlap to produce composite reflections from a series of closely spaced reflectors. A seismic trace is therefore actually an interference pattern composed of thousands of individual reflections.

\section{MARINE FIELD TECHNIQUES}

Figure 2 shows the basic recording set-up for land shooting. Figure 5 illustrates the basics of marine seismic recording.

\subsection{The seismic source}

The seismic source on a marine survey usually consists of a group, or array, or airguns (Fig. 6). An airgun is a compressed-air device. The main air chamber is filled with compressed air, usually at 135 bars. The air is then released instantaneously through a valve, producing an explosive rush of air. The first explosion is followed by several pulses, produced by oscillation of the resulting air bubble. The period of oscillation depends on the volume of the air bubble, and therefore on the volume of the airgun chamber. In order to minimize this "bubble oscillation", several airguns of different chamber sizes are used together in the water and fired simultaneously. The initial explosion of all the airguns takes place at the same time, but the bubble oscillations of the different size airguns cancel one another. This produces a shorter, more discrete pulse. Other marine sources are based on dynamite, steam, and propane as sources of seismic energy.

\subsection{The receivers}

The seismic receivers in a marine survey are pressure sensors, called hydrophones. The sensor element is a piezoelectric crystal. As in land seismic work, groups of hydrophones are used rather than individual hydrophones, in order to attenuate horizontally travelling noise such as energy travelling through the water, and refractions. A commonly used geometry is a $2400 \mathrm{~m}$ long streamer towed behind the ship. This is divided into 48 sections, each $50 \mathrm{~m}$ long, and each comprising one hydrophone group. A typical group consists of 33 hydrophones at $1,5 \mathrm{~m}$ spacing. The outputs of the individual hydrophones in a group are comnbined in a series - parallel arrangement to give one output signal, and the signals from the $\mathbf{4 8}$ groups are fed along the streamer to the ship.

\subsection{The recording instruments}

On board ship the signals are fed to a recording system where they are amplified and filtered, with a band-pass typically of 8 to $64 \mathrm{~Hz}$ (3 decibel down points).

The low-cut filter is to cut out low-frequency noise generated by the sea swell and by turbulence in the water. The high-cut filter has a steep slope ( 72 decibels per octave) and is to prevent aliasing of high frequencies during digital sampling. After filtering, the 48 signals are digitally sampled at a rate of 4 milliseconds and stored onto a half-inch digital magnetic tape in multiplexed form. If higher-fre- quency information is required, a sample interval of 2 milliseconds is used, with a $124 \mathrm{~Hz}$ high-cut (antialias) filter. These magnetic tapes are then ready for processing at an on-shore computer centre.

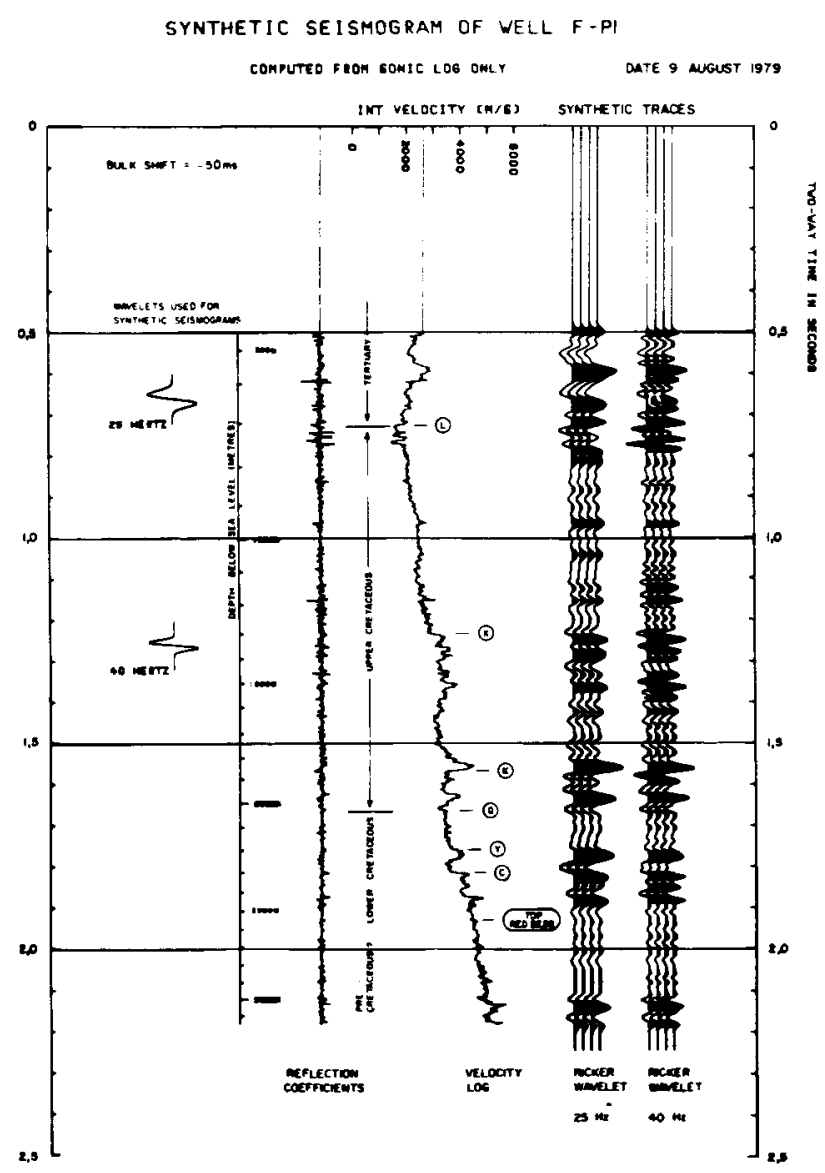

FIGURE 4b. The synthetic seismograin calculated from the actual velocity distribution in well $\mathrm{F}-\mathrm{PI}$ on the South African continental shelf, south of Mossel Bay. A constant density was assumed, and the same wavelets were used as in Figure 4a. The traces have been moved up by 50 milliseconds, similar to Figure $4 a$.

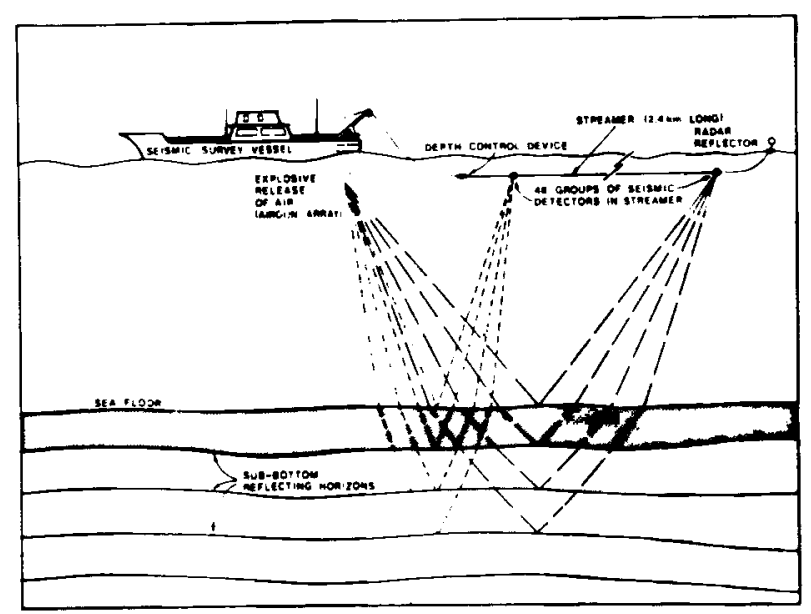

FIGURE 5. The recording layout in a marine reflection seismic survey. 

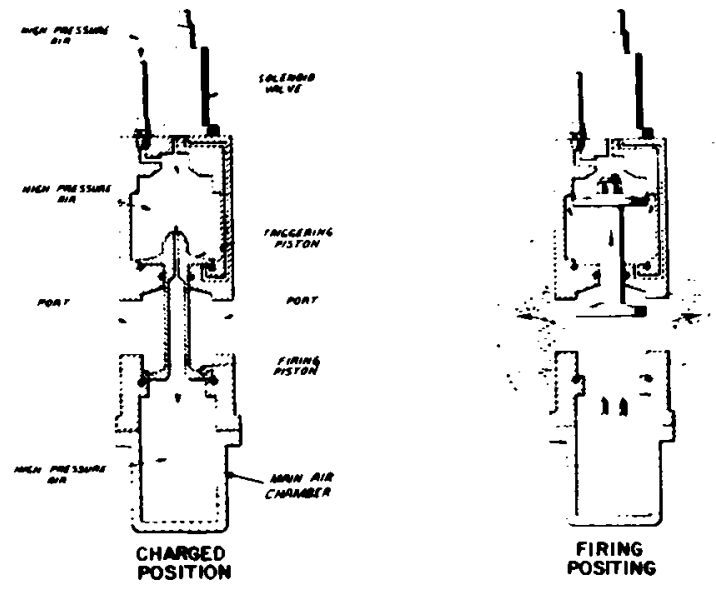

FIGURE 6. A cross section through an airgun used in marine seismic surveys. (After Luskin, ${ }^{7} p .4$ )

\subsection{Navigation}

The navigation of the ship during a survey is done using a shore-based radio navigation system such as Shoran, Decca Hi-Fix, or Syledis. In addition, satellite navigation is often used as a check. Navigation accuracy is usually in the order of $20 \mathrm{~m}$ at ranges of up to $200 \mathrm{~km}$ from the shore.

\section{COMMON-DEPTH-POINT RECORDING ANI PROCESSING}

\subsection{The reason for $C D P$ recording}

One of the major problems which is encountered in reflection seismic surveys is the presence of noise on the records. Noise interferes with the reflection signals, and high-level noise can even totally swamp the signals.

Noise on a seismic record has several origins. Much of the noise is random. This is produced by factors like swell and water turbulence in marine records, and wind on land records. Such noise is usually not coherent from one trace to another. Another class of noise is coherent noise, which can be seen as a coherent waveform moving across a record from trace to trace. Coherent noise is usually generated by the shot. On land records this shotgenerated noise is usually produced by refracted waves travelling in the shallow layers, and by surface waves, which are low-frequency dispersive waves travelling outwards from the shotpoint in the nearsurface layers (also called "ground roll"). In marine surveys, common sources of coherent noise are shallow refractions and energy travelling through the water layer, produced either by the recording ship or by other nearby ships.

Geophones or hydrophones are combined in groups, or arrays, to attenuate these types of noise, as mentioned earlier, but this is often not enough. Another technique which is used to reduce noise is called "common-depth-point shooting" (CDP shooting).

\subsection{The CDP method}

When the CDP method is used in marine surveys, shots are fired typically at a $25 \mathrm{~m}$ interval when using a $2400 \mathrm{~m}$ long streamer of 48 hydrophone groups.
COMMON DEPTH POINT MODEL

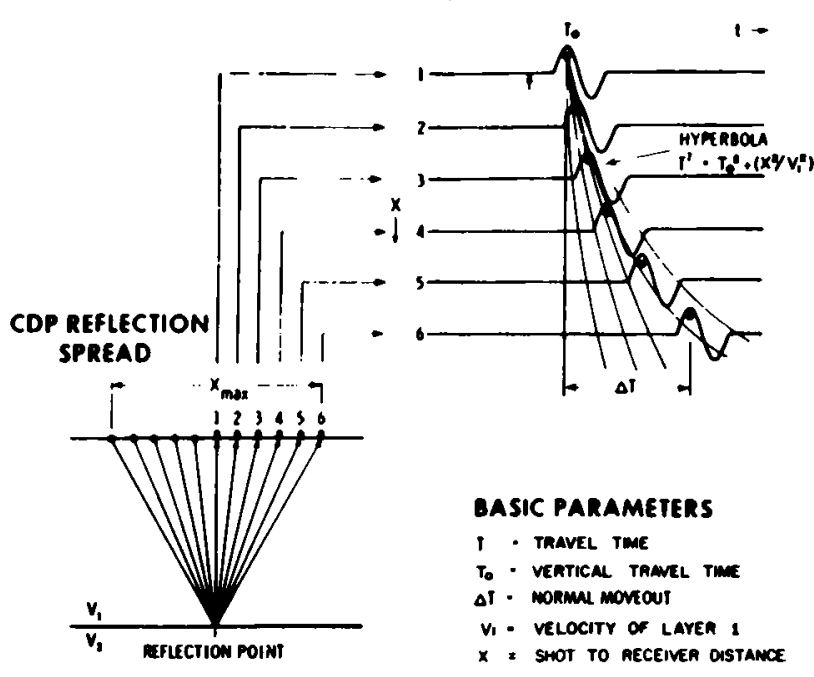

FIGURE 7. The geometry of six-fold commondepth-point (CDP) recording. Six seismic traces, each with different source and receiver positions, all have the same reflection point. The group of six traces is called a CDP gather. (Affer GSI fig. 2)

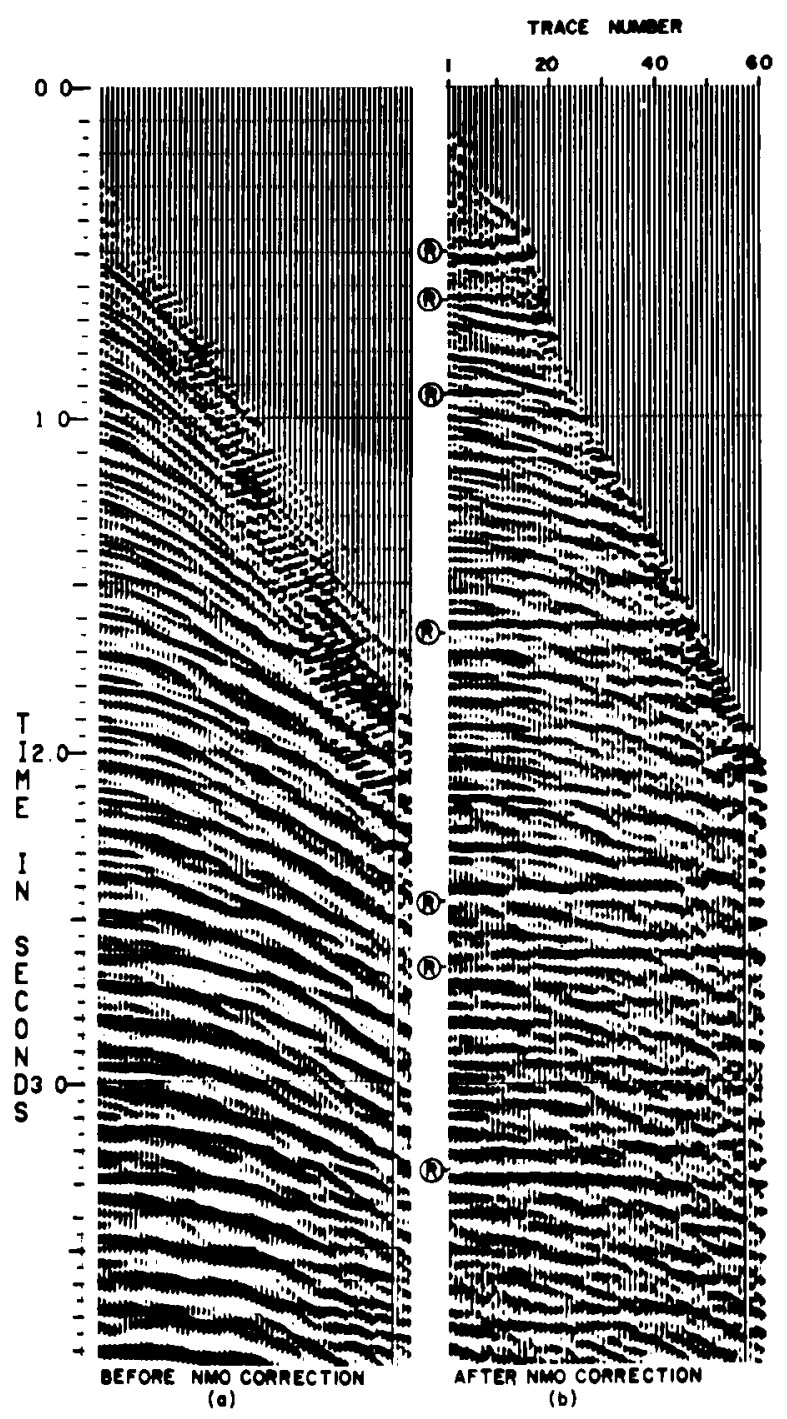

FIGURE 8. A 60-fold CDP gather, before and after NMO correction. In Figure (a) no correction has been applied, and the reflections are curved. In figure (b) the NMO correction has been applied, and primary reflections are now horizontal (marked $R$ ). 
There is thus an overlap of about 98 per cent between adjacent records. This geometry produces a 48 -fold stack. Using this recording geometry, it is possible during the computer processing to select individual seismic traces from successive records which have the same sub-surface reflection point (see Fig. 7). Each trace has a different source-to-receiver distance, but the same reflection point. Figure 7 shows a group of 6 traces for one reflectin point, arranged in order of increasing shot-to-receiver distance. This group of traces is called a "CDP gather". The reflection again follows a hyperbolic curve, similar to the shape on a simple field record, given by the relationship

$\mathrm{T}^{2}=\mathrm{T}_{0}^{2}+\mathrm{X}^{2} / \mathrm{V}^{2}$

Thus all reflections lie along hyperbolic curves, whereas noise in general does not. This property is used to discriminate against the noise.

Figure $8 \mathrm{a}$ is a field example of a CDP gather. There are 60 traces here, recorded with a 60-group cable, compared to the 6 traces in Figure 7. The reflections can be seen following hyperbolic trajectories. In Figure 8b, a correction has been applied to the traces, called "normal moveout"' (NMO) correction. In this procedure, the traces are moved upwards in order to "flatten" all the reflections (i.e. make them horizontal). Since the curvature of the original reflections decreases with increasing time, the correction has to be a time-varying correction, amounting to a time-varying stretching of each trace. On the normal-moveout corrected group of traces (Fig. 8b), reflections are now horizontal, whereas noise is not. Random noise is scattered randomly on the traces, whereas coherent noise lines up obliquely across the group of traces. Several such oblique line-ups can be seen in Figure $8 \mathrm{~b}$. The horizontal line-ups in Figure $8 \mathrm{~b}$, some of which have been marked $\mathrm{R}$ in the figure, are primary reflection. The slightly curved line-ups in Figure $8 \mathrm{~b}$ are mainly multiple reflections, and will be described in the next section. Apart from the NMO correction, there is a difference in character between the reflections in Figure $8 \mathrm{a}$ and $8 \mathrm{~b}$. This is because an additional process, deconvolution filtering, has been applied to Figure 8b. Deconvolution will be described in a following section. The upper parts of the traces have also been cut out in Figure $8 \mathrm{~b}$, because those parts of the traces consist mainly of noise.

The traces in the CDP gather are then summed. The reflections, being horizontal, are in phase and therefore add constructively, whereas the noise and multiple reflections are out of phase and are attenuated. The result is a "stacked" seismic trace.

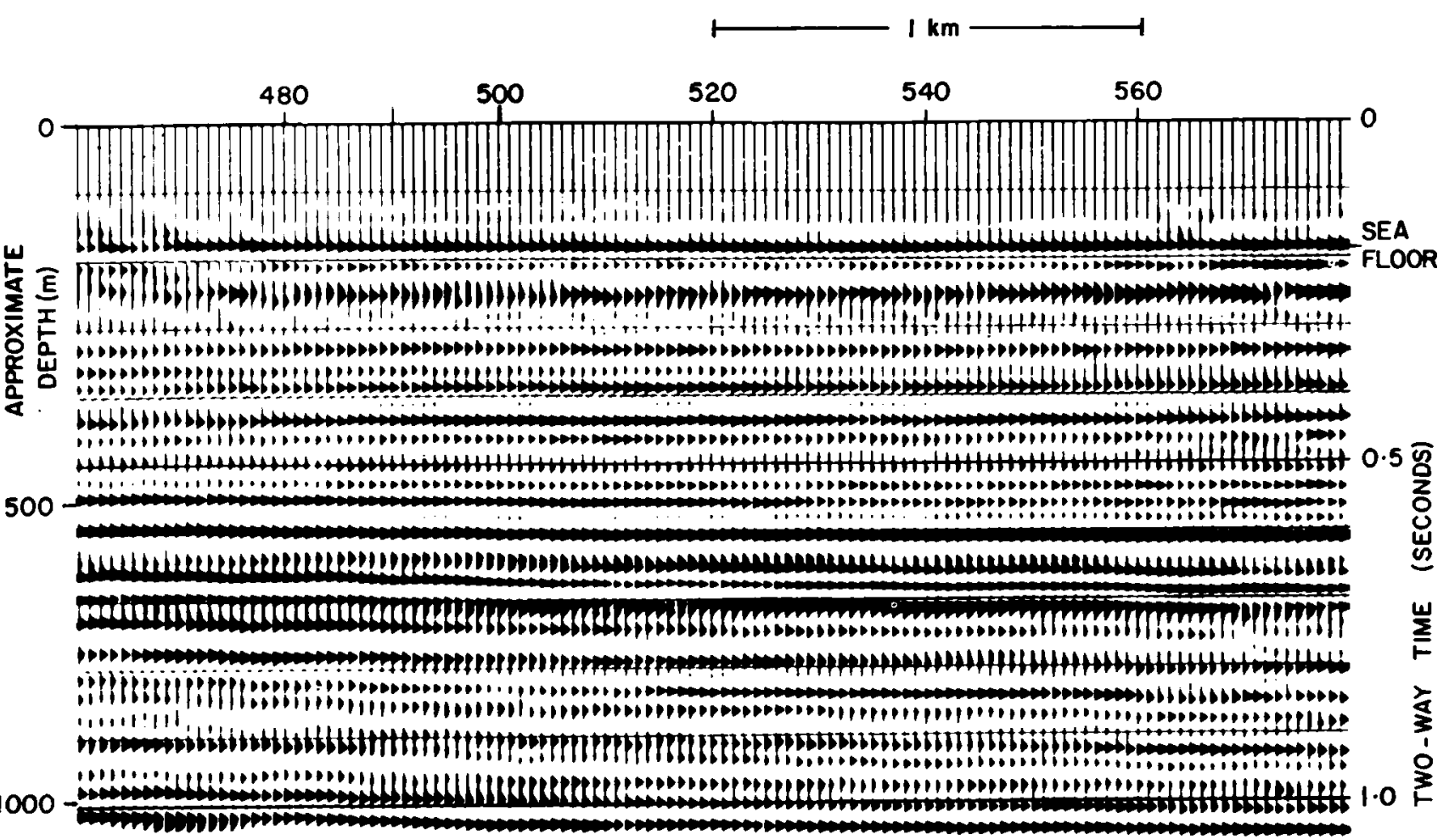

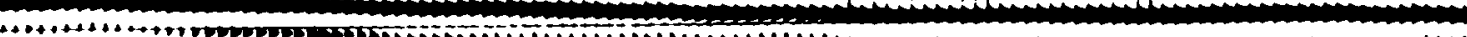

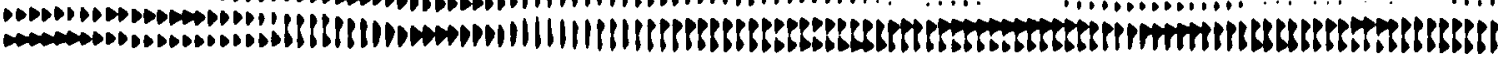
D.

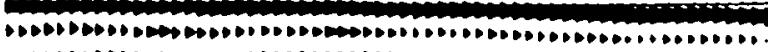

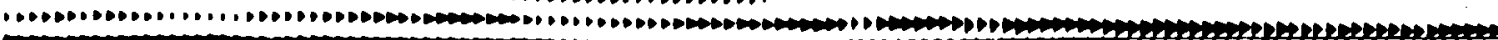

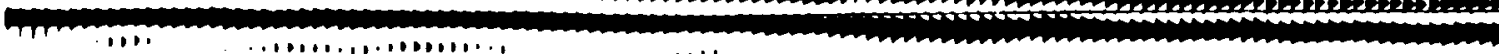

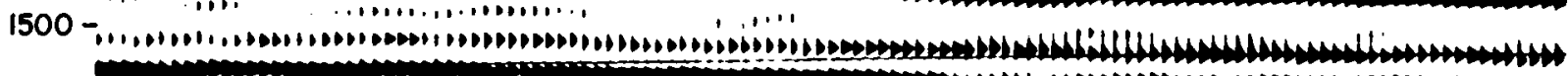
Irmm

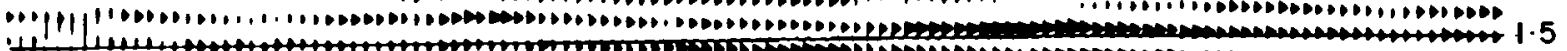

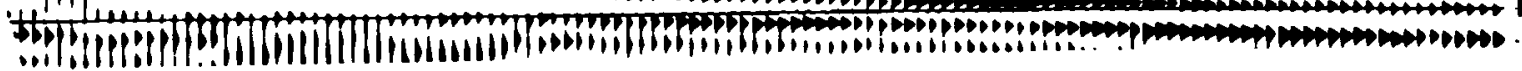

FIGURE 9. A seismic record section. The time scale is on the right, and approximate depth scale (non-linear) is on the left. 
Similarly for all the other reflection points, at $25 \mathrm{~m}$ intervals, stacked seismic traces are produced. The stacked traces are displayed next to each other to produce a "seismic record section" (Figure 9). A seismic record section can be thought of as a pseudo crosssection through the earth. The horizontal scale is distance, and the vertical scale, time, is a non-linear representation of depth. The almost-horizontal events in Figure 9 are reflections from sedimentary interfaces. In Figure 10, an unstacked record section is shown (Fig. 10a) with the corresponding stacked section (Fig. 10b). There is a dramatic improvement in the stand-out and continuity of the reflections on the stacked section.

CDP stacking is one of the most powerful techniques for noise reduction in reflection seismic surveys, and most surveys today are done using CDP stacking. In land surveys the fold of stack is usually 6 to 12 (this is the number of traces which are summed to produce one stacked trace). In marine surveys recording is much less expensive, and a higher fold of stack can consequently be used: stack folds of 48,60 and 72 are common.

\subsection{Velocity analysis}

Equation (2) shows that, for horizontal layering, the travel time for a reflection depends on the average seismic velocity (V) through the overlying rocks:

$\mathrm{T}^{2}=\mathrm{T}_{0}^{2}+\frac{\mathrm{X}^{2}}{\mathrm{~V}^{2}} \ldots$

From this equation one can see that the hyperbolic curvature of a reflection depends on the average velocity (strictly the "RMS average velocity", which is slightly higher than the average velocity). For low velocity the reflection has greater curvature than for high velocity.

The interval velocity of sedimentary rocks depends on the lithology, state of compaction, degree of cementation, porosity, and various other factors. The interval velocity usually increases with depth because of increase in overburden pressure, degree of compaction, and cementation (see Figure 4b). Therefore, the average velocity also increases with depth. Velocities also vary laterally as a result of varying lithology and structural setting of the sediments.

It is important to know the curvature (and thus the average velocity) of all reflections on a seismic profile, because this is the basis of the NMO correction. Thus the output of the stacking procedure depends on a knowledge of the average velocities. Average velocity can be measured accurately in boreholes, but boreholes are usually too few and far between. In practice the normal moveouts are estimated from the seismic records themselves. A CDP gather, such as the one in Figure 8a, is used for this purpose. At a certain two-way time, the computer searches for coherent seismic events along families of hyperbolae on the CDP gather, each hyperbola corresponding to a different velocity. The hyperbola which is found to have the highest coherence is picked as the one cor- responding to a primary reflection. This process is then repeated a small increment of time (about 50 $\mathrm{msec}$ ) further down the CDP gather, until the NMO (and thus velocity) has been estimated all the way down the record. The output of this analysis is velocity as a function of two-way time. Such velocity analyses are typically done every $3 \mathrm{~km}$ along a seismic line during the computer processing. The velocity functions are then interpolated between velocity analysis points to give a space-and time-varying velocity field. This velocity field is then used as input to the NMO correction procedure, and the NMO correction is followed by stacking, as described earlier.

\subsection{Attenuation of multiple reflections}

A very severe problem in some areas, especially offshore, is multiple reflections. A multiple reflection is a reflection which travels along the usual path to and from a reflector, but is then reflected back off the surface and repeats the same travel path (Figure 11). Multiple reflections with more complicated travel paths also occur. Since the multiple reflection in Figure 11 travels through the shallow part of the section, its normal moveout will correspond to the average velocity $\left(V_{1}\right)$ down to reflector $A$. The primary reflection in Figure 11 has approximately the same two-way travel time as the multiple, but its normal moveout is determined by the average velocity down to reflector $B$. If the velocity increases with depth, the average velocity for the primary would be higher than that for the multiple, and therefore the primary has a smaller normal moveout time (i.e. is less curved) than the multiple. Figure 12 is a synthetic example of a CDP gather after NMO correction. The correction applied coresponded to the primary velocity, so the primary reflection has been "flattened", whereas the multiple, because of its lower velocity, has been undercorrected and has some residual curvature. When the six traces are summed the primary adds constructively, whereas the multiple adds destructively, and it is attenuated and smeared out.

Figure 13 shows the effect of multiple attenuation on a stacked section. The section consists of a horizontally layered interval down to about $1.2 \mathrm{sec}$. At $1.2 \mathrm{sec}$ there is an unconformity, and the underlying beds are steeply dipping. The multiple reflections in Figure 13a have been very effectively removed by stacking. In Fig. 13b the same section has been restacked using the multiple velocity function for NMO correction, instead of the primary velocity function. The result is that the multiples have been enhanced and the primaries attenuated. It can be seen that the shallow beds above the unconformity have generated multiples which dominate the deeper section, obscuring the dipping primaries below the unconformity.

\section{COMPUTER PROCESSING}

The purpose of computer processing seismic data is two-fold. Firstly it is to reduce noise and multiples, and to improve resolution of detail. Secondly, it is to remove geometrical distortion and perhaps to present the results as a true depth profile. 


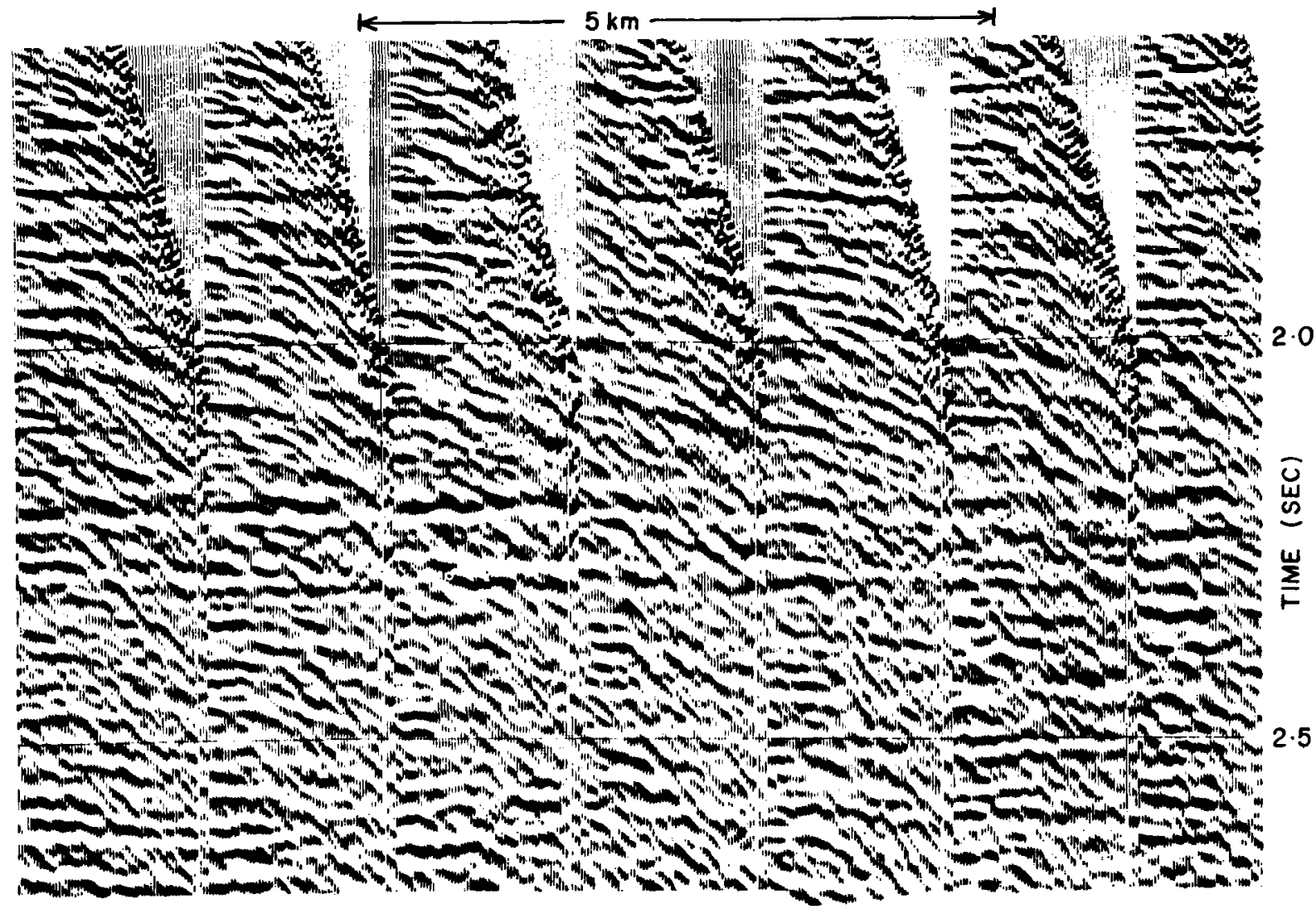

FIGURE 10. A single-fold (i.e. unstacked) seismic record section (Figure a) and the corresponding 60-fold stacked section (Figure b).

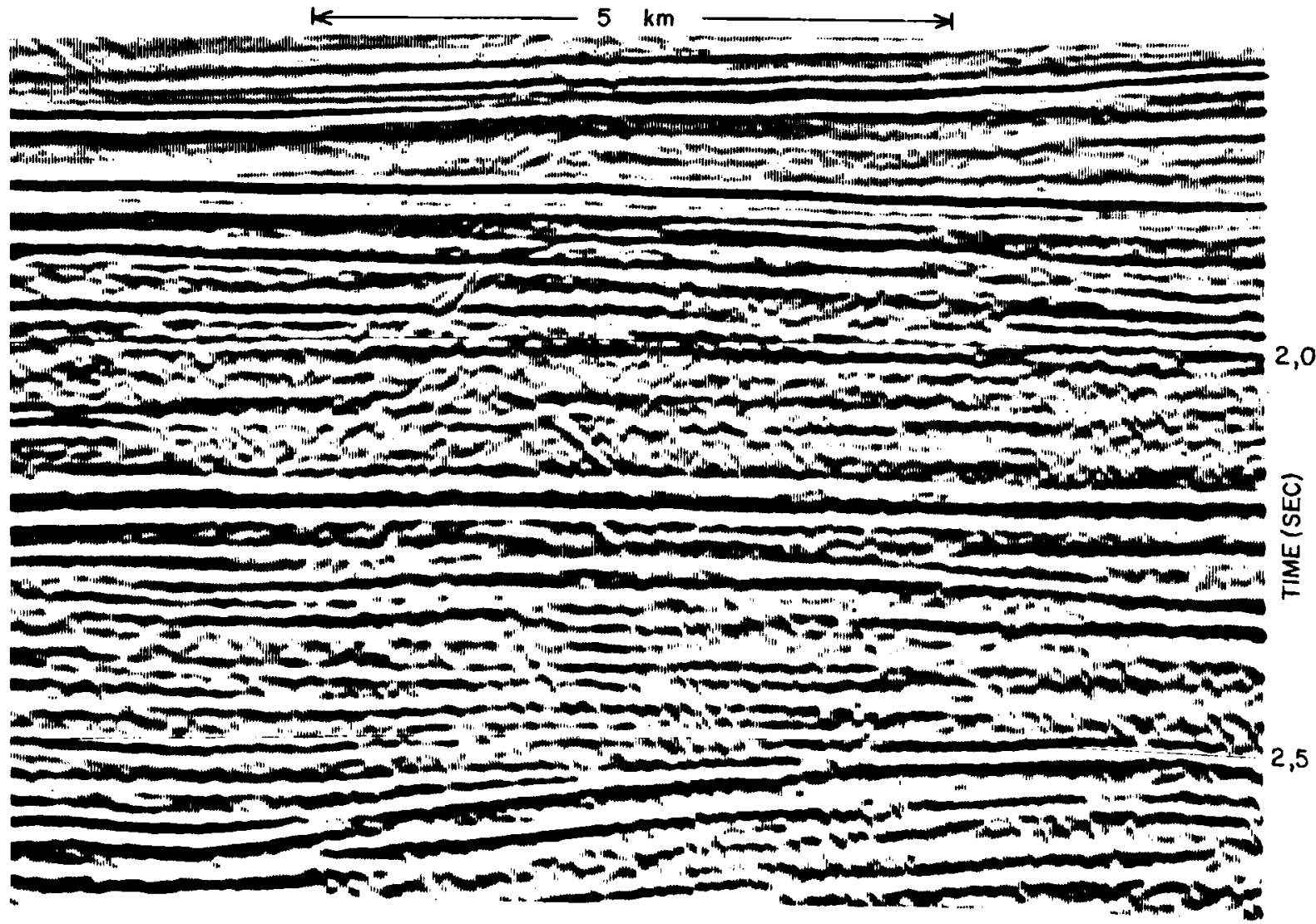




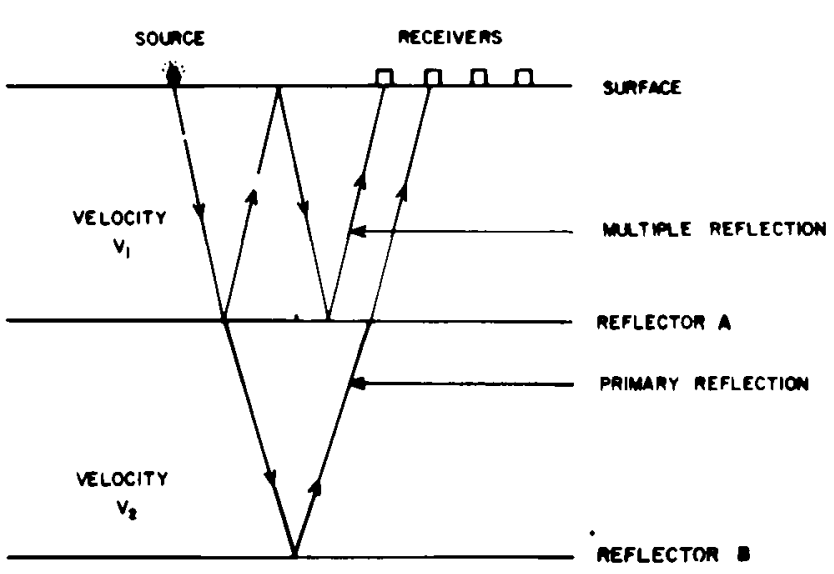

FIGURE II. Raypath diagram showing a primary reflection and a multiple reflection.

\subsection{Removal of noise and multiples}

The most powerful noise-reducing technique is CDP stacking, which has already been discussed. A second noise-reducing procedure which is usually used is band-pass filtering. The seismic signals have a frequency content roughly in the range 8 to $60 \mathrm{~Hz}$, The exact frequency limits vary from area to area, and also depend on the techniques used. Band-pass filtering is applied to cut out noise which falls above and below the seismic signal frequencies. The filtering is done by convolving (or filtering) each seismic trace in the computer with a filter operator. The ope- rator is usually designed to have zero phase response at all frequencies. This is an advantage over analog filters which produce phase distortion and therefore distort the shape of the reflection signals.

Another procedure which is very commonly used is deconvolution. This is to remove shallow-water multiplies in marine records, and to improve resolution. There are many factors which distort the reflection signal and change it from the narrow wavelet which was emitted by the dynamite charge or airgun array into a wavelet which is several cycles long. This drastically reduces the ability to resolve fine detail such as thin beds and sedimentary pinch-outs. The most harmful of these distorting factors is shallow-water multiples in marine surveys, also called water reverberation. The velocity difference between primaries and multiples is not big enough in this case for CDP stacking to remove the multiples effectively. One can consider the multiple generating mechanism as a filter which has been applied to the seismic traces. Using the autocorrelation function of a seismic trace, an inverse filter can be designed which will counteract the effect of the multiple-generation filter. This is termed deconvolution filtering.

If the Fourier transform of the multiple generation filter is $F(f)$, where $f$ is frequency, the inverse filter in principle is $1 / F(f)$. A class of filters called Wiener filters has been developed to do this type of filtering in the time domain. Alternatively it can be done in the frequency domain by transforming the seismic

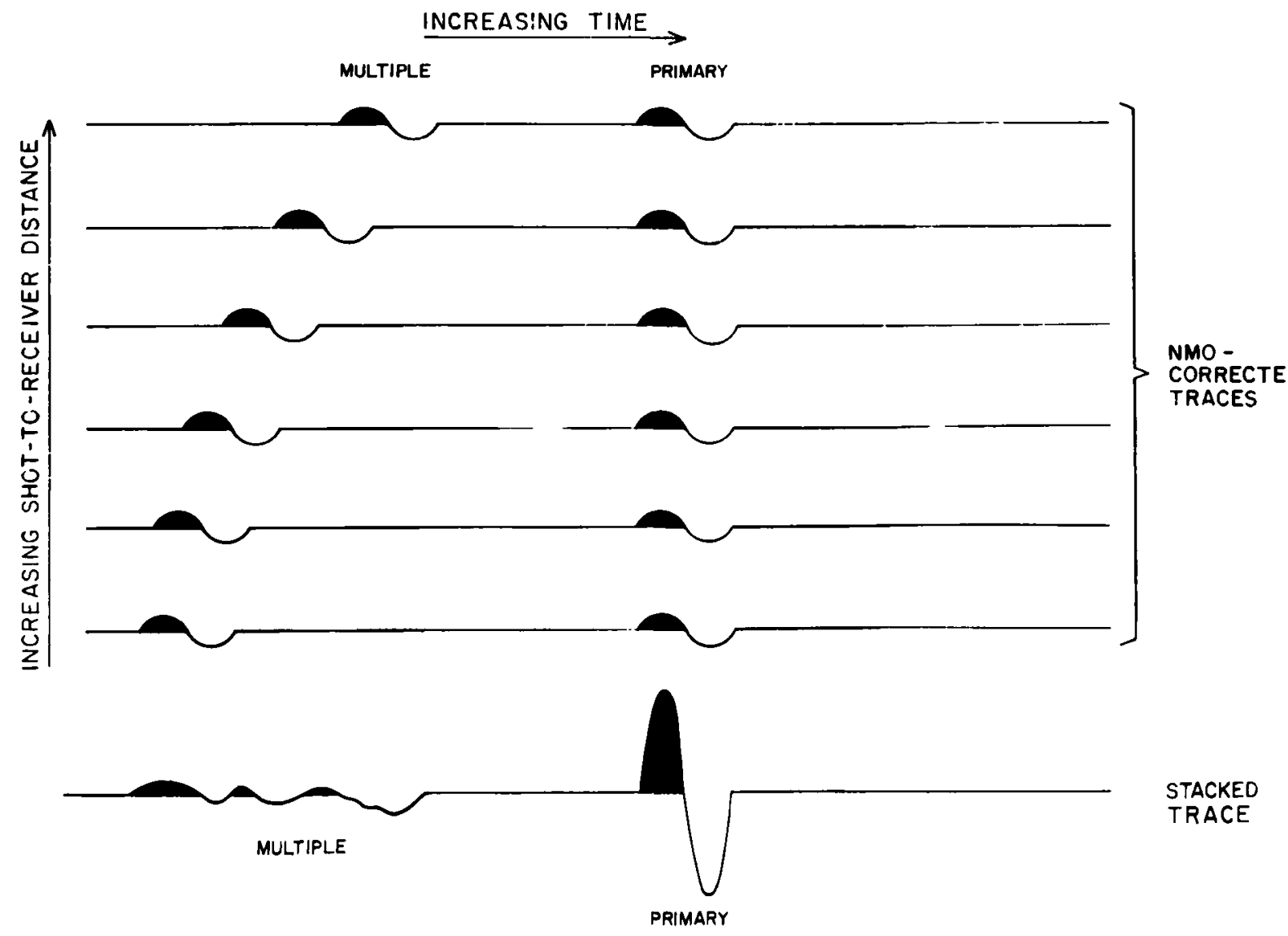

FIGURE 12. The upper 6 traces comprise a CDP gather which has been NMO-corrected. The lower trace is the sum of the 6 traces in the CDP gather: the stacked trace. 


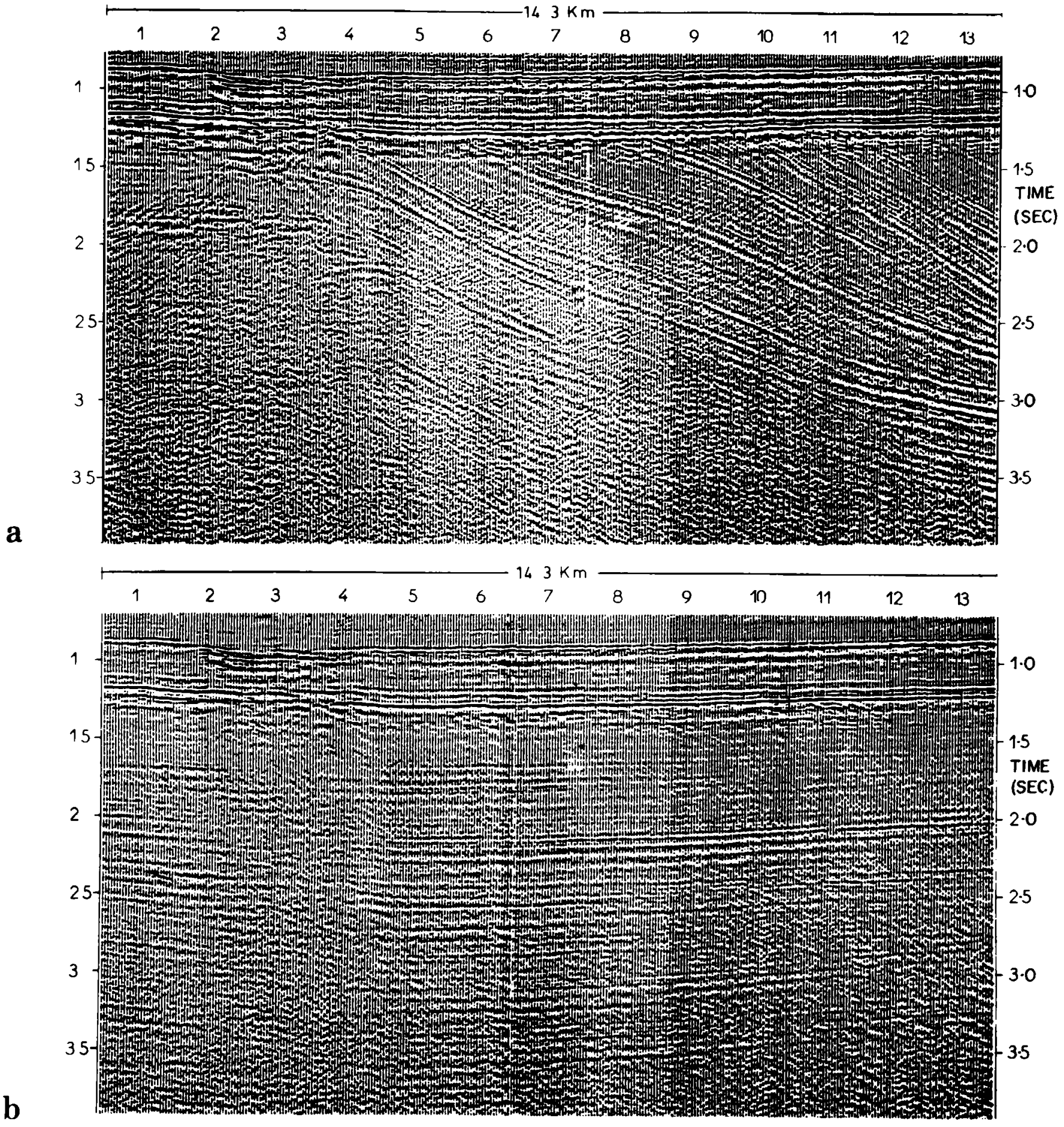

FIGURE 13. Figure a is a stacked seismic section. In Figure b the same data have been re-stacked using velocities corresponding to the multiple reflections, thus enhancing the multiples and attenuating the primaries. (After Garotta and Michon, ${ }^{9}$ p. 592)

traces into the frequency domain and applying the filter $1 / F(f)$.

Figure 14 demonstrates the effect of deconvolution filtering. The seismic section on the left, before deconvolution, has been affected by strong water reverberation which has had the effect of turning each reflection into a series of about 4 cycles of a sinusoidal wave. This makes it dificult to resolve features such as the pinch-out at 1.0 second near the left-hand side of the section.

Figure $14 \mathrm{~b}$ has been deconvolved. The reflections have been contracted by reducing the number of cycles of each event, and details of the pinch-out at 1 second can be seen more clearly.

\subsection{Correction of geometrical distortion}

On a seismic record section, seismic traces are displayed below the surface positions where they were recorded. However, when the beds are dipping the reflection points are not vertically below the observation poins but displaced up-dip (see Figure 15). Since the reflections are displayed vertically below the observation points, the structural appearance of reflectors on a seismic section is distorted. This distortion increases with increasing dip. In extreme cases a steep syncline can look almost like an anticline because the flanks overlap each other on the seismic section.

To correct this distortion, a two-dimensional procedure called migration is applied to the seismic sec- 
tion. The most common method is a finite-difference procedure based on the elastic wave equation. The result is to place the reflectors in their correct spatial positions on the seismic section. Figure 16 is an example of a migrated seismic section over a faulted syncline (at $1.6 \mathrm{sec}$ in the centre of the section). Before migration, the flanks of the syncline appear smeared over a long portion of the section, obscuring the true nature of the syncline.

To produce a true depth profile, the vertical scale of the seismic section can be converted from time to depth by multiplying by the appropiate velocity function. The velocity function usually varies laterally, and can be obtained from well-velocity surveys or from the velocity analyses performed on the seismic records themselves.
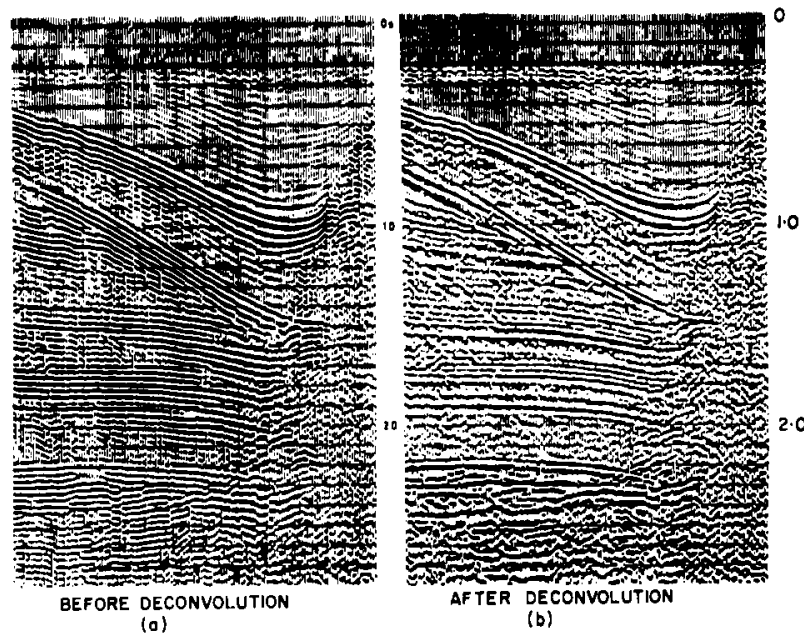

FIGURE 14. A seismic section before and after deconvolution filtering, to remove water reverberation. (After Dobrin, ${ }^{2}$ p. 192)

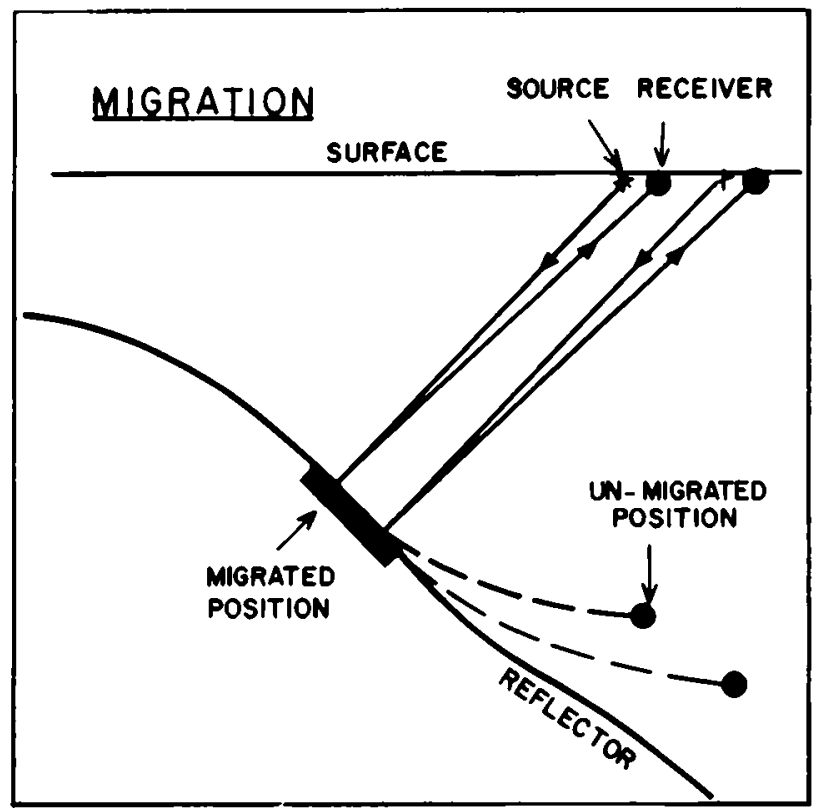

FIGURE 15. Diagrain showing the migrated and unmigrated positions of $a$ dipping reflection on a seismic section.

\section{EXAMPLES, AND INTERPRETATION}

In this section some examples of migrated seismic sections will be discussed from the Gamtoos basin on the South African continental shelf. The location is about $35 \mathrm{~km}$ offshore, due south of Port Elizabeth. The geological succession here consists of a thick secton of Cretaceous sediments, overlain by a few hundred metres of Tertiary sediments. The Cretaceous rocks consist mainly of sandstone, siltstone and shale, and are potential reservoirs of oil and gas. Underlying the Cretaceous succession are older rocks of the Cape and Malmesbury groups, which are nonprospective from the point of view of hydrocarbons.

Figure 17 is a migrated west-east section across the eastern margin of the basin. The eastern boundary of the basin is a fault with enormous throw: the Gamtoos fault. The fault can be seen clearly on the section. The upthrow side of the fault (east) consists of "basement" rocks of the Cape group, and the downthrow side (west) consists of steeply dipping LowerCretaceous and possible Jurassic rocks. There are two prominent unconformities on the section. Horizon $\mathrm{A}$ is the base of the Upper Cretaceous, and Horizon $\mathrm{C}$ is of Mid-Lower Cretaceous age. East of shotpoint 400 Horizon $C$ is an erosional unconformity, and pre-Horizon $\mathrm{C}$ sediments sub-crop directly below the Upper Cretaceous. In the western half of the section sediments in the A-to-C interval onlap onto the Horizon $\mathrm{C}$ unconformity, indicating a period of marine transgression. An approximate aepth scale has been given on the right-hand side of the section. The sea floor depth is about 130 metres, and the total thickness of the Mesozoic sediments is in excess of $7000 \mathrm{~m}$.

Figure 18 is a close-up of Horizon $\mathrm{C}$ on another seismic line in the same area. The sediments above the Horizon- $\mathrm{C}$ unconformity can be seen onlapping onto Horizon $\mathrm{C}$. The pre-horizon $\mathrm{C}$ sediments clearly were tilted before deposition of the overlying beds. Very fine detail can be seen in the parallel-layered sequence below Horizon $C$.

In Figure 19 the rocks below Horizon $C$ have been faulted by three normal faults. The post-Horizon $\mathrm{C}$ sediments again onlap Horizon $\mathrm{C}$, indicating marine transgression over a faulted topography. It is clear that the central fault has been active during postHorizon $\mathrm{C}$ time, producing a slight displacement in the sediments above Horizon $\mathrm{C}$. Some of the reflections below Horizon $\mathrm{C}$ show a distinctive character, which enables the interpreter to identify the same reflector on both sides of a fault. This applies especially to Horizon $\mathrm{T}$.

The structural interpretation of reflection seismic results consists of identifying reflectors in the zone of interest and then producing structure contour maps of these reflectors. Having a well in the vicinity is of great assistance to the interpreter in identifying the various reflectors. The ages of sediments penetrated in a well are usually determined using micropalaeontology. In the area of the seismic sections in Figures 17 to 19 , several potential hydrocarbon traps have been located: unconformity traps, such as the 

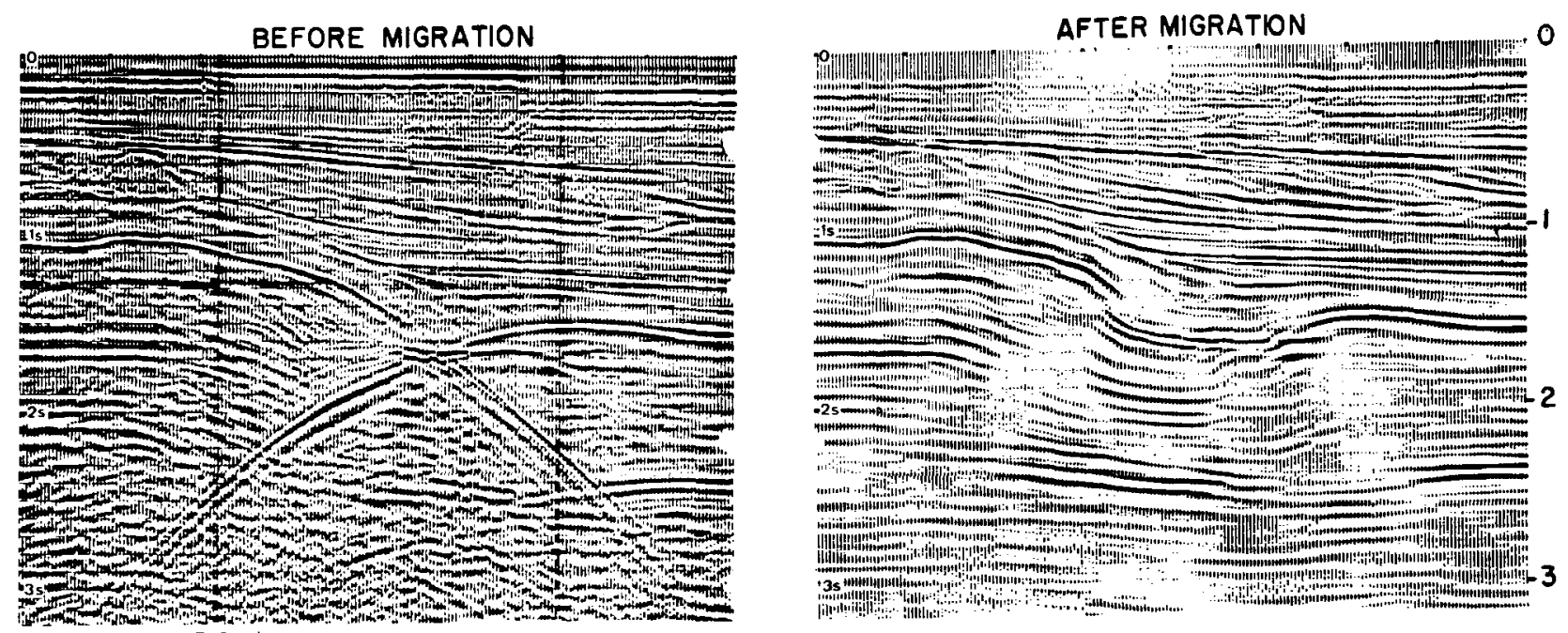

FIGURE 16. A record section before and after migration. Notice the faulted syncline in the centre of the section. (After CGG, ${ }^{10}$ p. 48)

sub-cropping sequence below Horizon $\mathrm{C}$ on the eastern part of Figure 17, and fault traps. To be an effective oil or gas trap, a trap structure must be closed in all directions, and very detailed structure contour maps need to be made to determine this. Usually contour maps are constructed in two-way travel time. But for the greatest accuracy, true structure contour maps need to be made: contours of depth to a particular reflector below sea level. To do this, a map of average velocity to the reflecting horizon must first be prepared. The velocities are determined either from well-velocity surveys (if there are enough wells), or from seismic velocity analyses. The depth at each shotpoint is then calculated as the product of the average velocity at that shotpoint and the one-way travel time. The structure contour maps are then used as a basis, in combination with geological information, to plan an exploration drilling program.

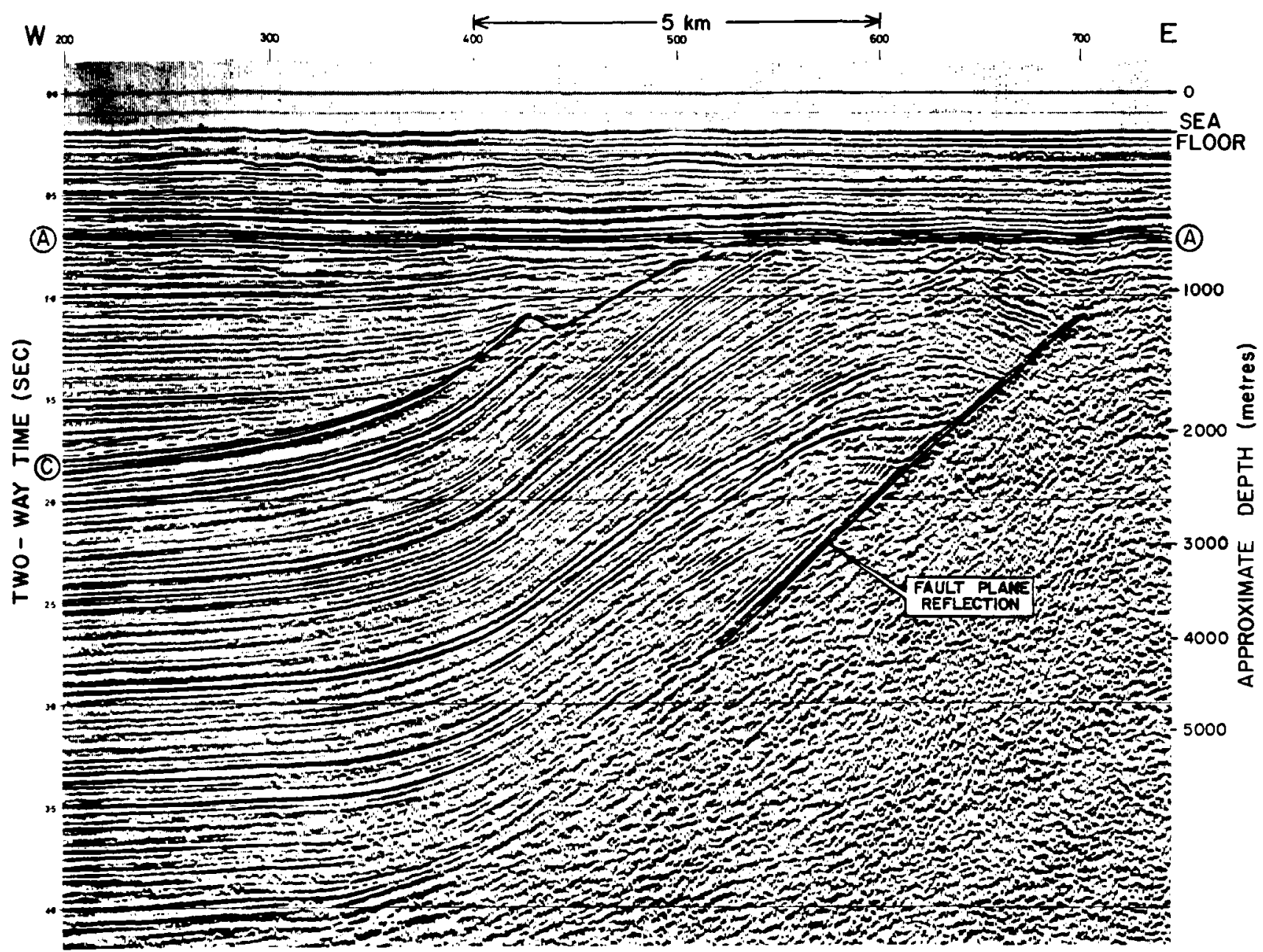

FIGURE 17. A west-east seismic section across the eastern margin of the Gamtoos basin, $40 \mathrm{~km}$ south of Port Elizabeth. $A$ and $C$ are unconformities. 
C.

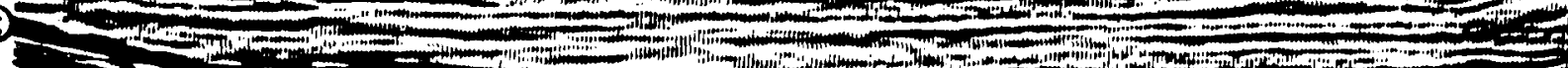

$5=-2,1-1=$

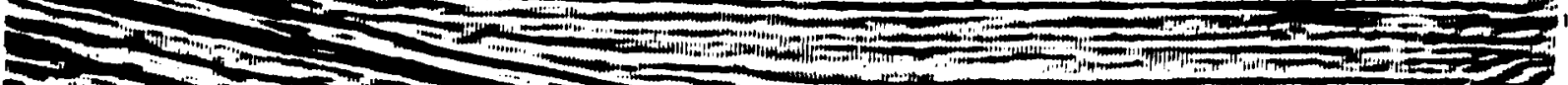

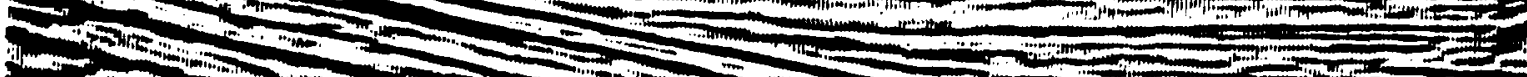

$2{ }_{2}$

$2=2-20$

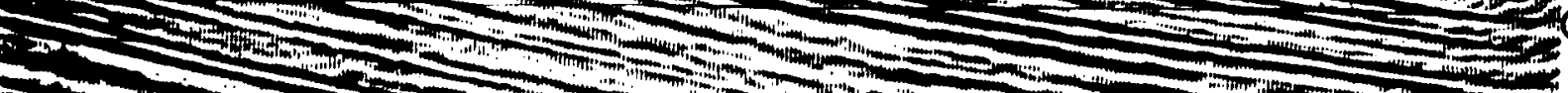

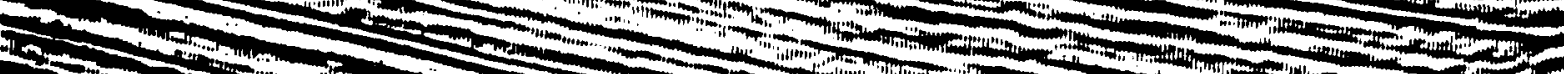

$2020=0$

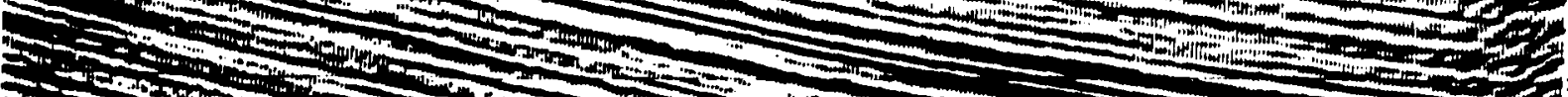

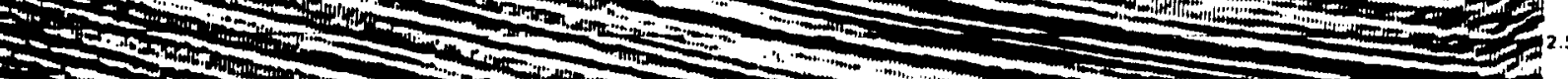

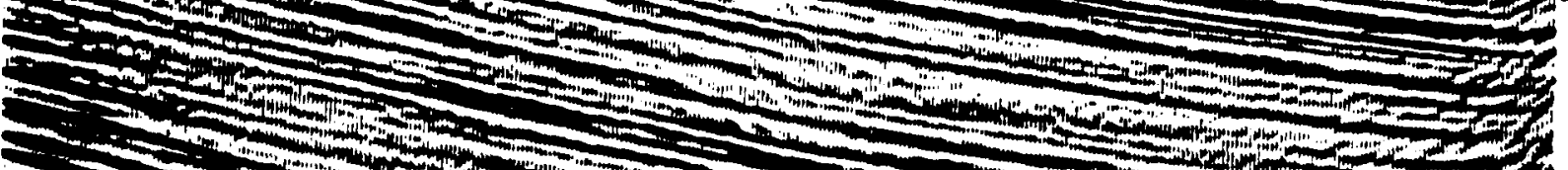

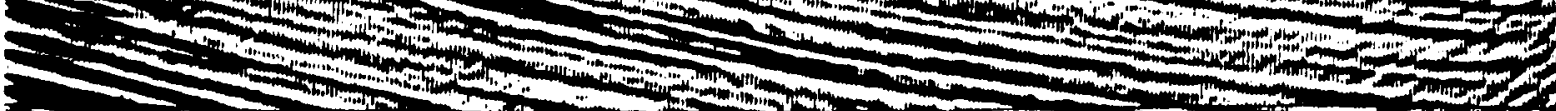

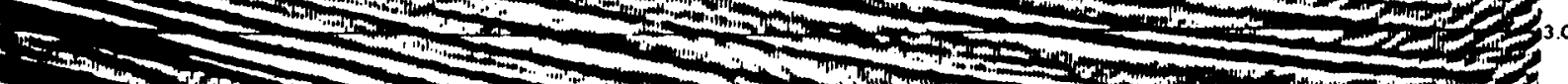

2.

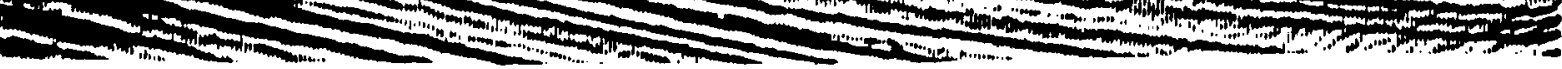

FIGURE I8. Close-up of the Horizon C unconformity. The overlying sediments are onlapping onto Horizon C.

S

$5 \mathrm{~km}$

N

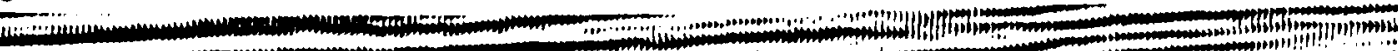

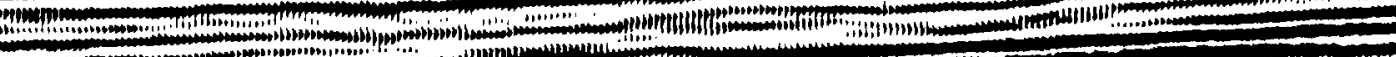

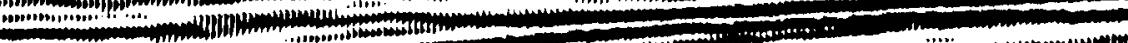
(1) A 1)

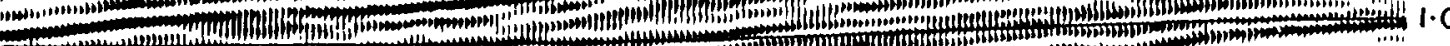

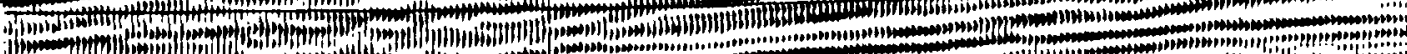

I $\bar{E}$ : illow

5 E E

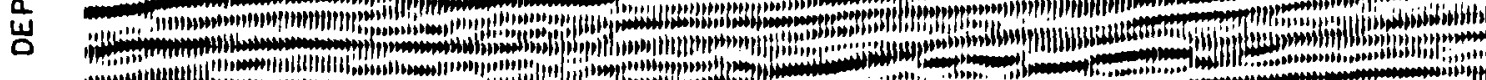

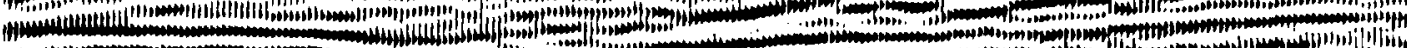

L

疍 (C)

$\frac{1}{x} \quad{ }_{0}$

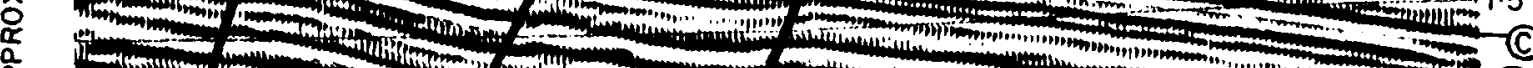

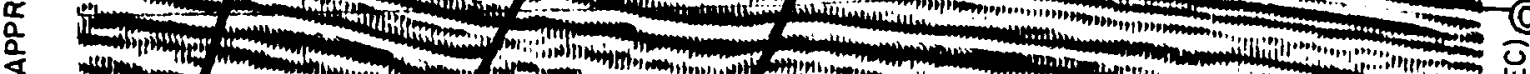

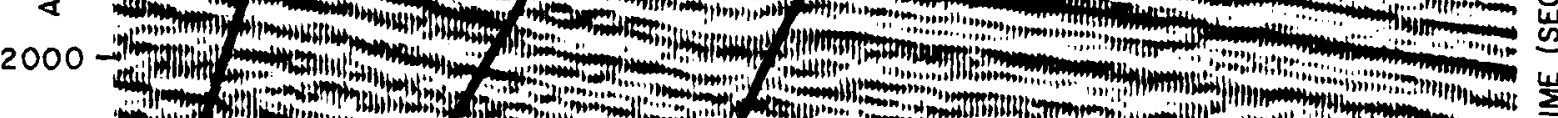

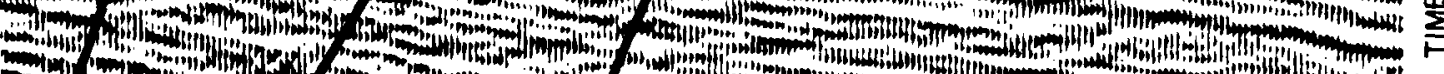

(1) 110 m

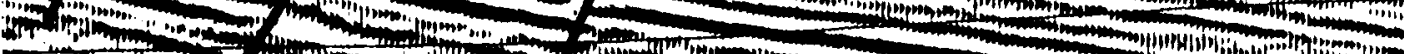
H.

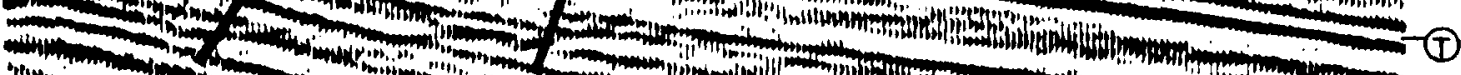
dewn

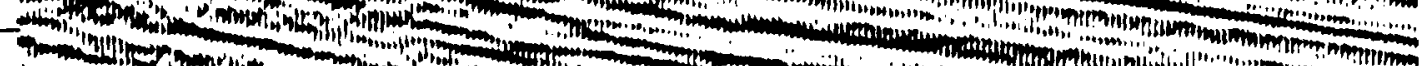

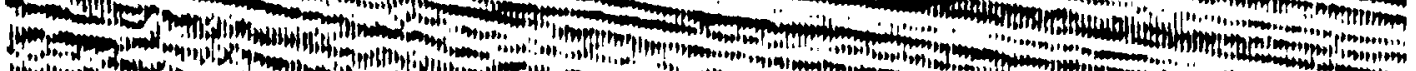

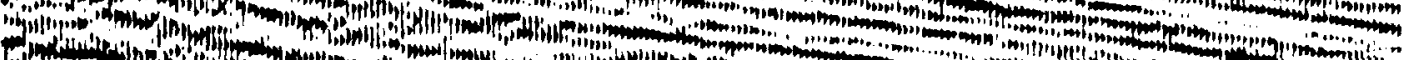
D.

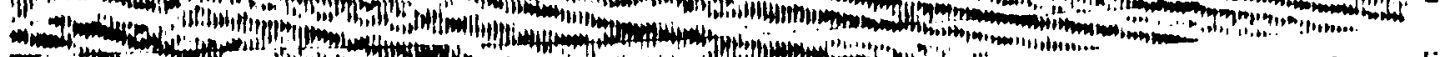
J"1 
Oil or gas can usually not be detected directly with the reflection seismic method. But in some circumstances the presence of gas can be deduced. This is usually only possible in the case of a very porous reservoir rock, such as sandstone, which is saturated with gas. If the reservoir lower down in the trap structure is water-saturated, the gas-water contact can sometimes produce a reflection, known as a "flat spot". Thus if a horizontal high-amplitude reflection is seen in a sequence of dipping reflections, this is an indication that it might be from a gas-water contact. The interface between the gas-saturated reservoir and the surrounding rocks, either shales or watersaturated reservoir rocks, sometimes produces a very high amplitude reflection known as a "bright spot". This is caused by highly contrasted acoustic impedances across the interface, due to anomalously low velocities and densities in the gas reservoir. But the only way of determining for certain if there is oil or gas is by drilling a well.

\section{ACKNOWLEDGEMENTS}

The author would like to thank the Management of SOEKOR (PTY) LTD. for permission to publish this article. Hearty thanks are due to the SOEKOR
Drawing Office for making all the illustrations. Also, the author is grateful to G.C. Smith for reading through the manuscript and offering suggestions.

\section{REFERENCES}

1. Whitmire, M.G. (1979). Geophysical Activity in 1979, Geophysics, V. 44, p. 1740.

2. Dobrin, M.B. (1976). Introduction to Geophysical Prospecting. McGraw Hill Book Company, New York.

3. Waters, K.H. (1978). Reflection Seismology, a tool for energy resource exploration. Wiley and Sons, New York.

4. Holmes, Arthur (1957). Principles of Physical Geology. Thomas Nelson and Sons Ltd., London.

5. Landes, K.L. (1959). Petroleum Geology. Wiley and Sons, Inc., New York.

6. Coffeen, J.A. (1978). Seismic Exploration Fundamentals. PPC books, Tulsa.

7. Luskin, Bernard (1968). The PAR airgun. Bolt Associates, 10 Fitch St., Norwalk, Conn.

8. Geophysical Service, Inc. (1974). Velocity Searching Techniques, G.S.I. Technical bulletin.

9. Garotta, R., and Michon, D. (1967). Continuous Analysis of the velocity function and of the moveout corrections, Geophysical Prosp., v. 15, n. 4, p. 592.

10. Compagnie Gènèrale de Geophysique (1971). Seismic Processing. CGG Technical Bulletin, Reference 71-02A. 